\title{
Prevalence of postoperative delirium according to the intraoperative general anesthetic agents in patients undergoing cardiac surgery: A retrospective and propensity-score matched study
}

\section{Hyun-Jung Shin}

Seoul National University Bundang Hospital

\section{Soo Lyoen Choi}

Seoul National University Bundang Hospital

Hyo-Seok Na ( $\sim$ hsknana@gmail.com )

Seoul National University Bundang Hospital https://orcid.org/0000-0003-0986-3243

\section{Research}

Keywords: sevoflurane, propofol, dexmedetomidine, cardiac surgery, postoperative delirium

Posted Date: September 30th, 2020

DOI: https://doi.org/10.21203/rs.3.rs-57423/v2

License: (c) (i) This work is licensed under a Creative Commons Attribution 4.0 International License. Read Full License 


\section{Abstract}

Background: Postoperative delirium (PD) is still an issue in post-cardiac surgery patients despite the constant efforts to reduce it. Although various risk factors for PD after cardiac surgery have been identified, there is limited clinical data regarding the effect of intraoperative anesthetic agents on the PD.

Methods: The medical records of 534 patients, who had undergone heart valve surgery or coronary artery bypass graft surgery with cardiopulmonary bypass (CPB) between January 2012 and August 2017, were investigated. They were divided into two groups according to the main anesthetic agent: sevoflurane with dexmedetomidine (sevo-dex group, $n=340$ ) and propofol (propofol group, $n=194$ ). The incidence of PD was evaluated as the primary outcome. PD was defined as the positive Confusion Assessment Method for the Intensive Care Unit during the intensive care unit stay. Patient-, surgery-, and anesthesia-related factors and postoperative complications were investigated as secondary outcomes. To reduce the risk of confounder effects between the two groups, 194 patients were selected from the sevo-dex group after propensity-score matching.

Results: After propensity-score matching, the incidence of PD was not significantly different between the sevo-dex (6.2\%) and propofol $(10.8 \%)$ groups $(P=0.136)$. In comparison of the incidence of each type of $P D$, only hyperactive PD occurred significantly less in the sevo-dex group than in the propofol group $(P=0.021)$. Older age, lower preoperative albumin levels, and emergency surgery were significant risk factors for PD.

Conclusions: The overall incidence of PD after cardiac surgery with CPB is not associated with the main anesthetic agents, sevoflurane and dexmedetomidine-based vs. propofol-based anesthesia. Only hyperactive PD occurred less frequently after in patients receiving sevoflurane and dexmedetomidine-based anesthesia.

\section{Background}

Delirium is associated with many adverse hospital outcomes, including increased mortality, nosocomial complications, poor one-year functional recovery, and even postoperative cognitive decline (Chaput and Bryson 2012; Saczynski et al., 2012). Postoperative delirium (PD) is still an issue in cardiac surgery patients despite the constant efforts to reduce it, such as various pharmacologic agents, reorientation, sleep protocols, early mobilization, nutrition, and so on (Evans et al., 2016).

Various risk factors for PD after cardiac surgery have been identified, such as advanced age, preexisting cognitive impairment, cerebrovascular disease, metabolic syndrome, and type and duration of surgery (Hollinger et al., 2015; Lin et al., 2012). However, little has been studied about the effect of intraoperative anesthetic agents on the PD in cardiac surgery, unlike in non-cardiac surgery (Miller et al., 2018). The occurrence of PD after cardiac surgeries was reported to be similar irrespective of the main anesthetic agents, inhalation agents or propofol (Jiao et al., 2019; Oh et al., 2017); however, early postoperative cognitive dysfunction was less in patients managed with inhalation anesthesia during cardiac surgery (Royse et al., 2011; Schoen et al., 2011).

In addition, it has been reported that dexmedetomidine could reduce PD in cardiac (Cheng et al., 2016; Djaiani et al., 2016; Maldonado et al., 2009) or non-cardiac surgery (Su et al., 2016; Xie and Xie 2018). Thus, when dexmedetomidine was added to inhalation anesthesia during cardiac surgery, it was wondered whether they could show an additional PD-sparing effect than propofol did. 
Accordingly, the aim of this retrospective study was to investigate and compare the incidence of PD after cardiac surgery according to the intraoperative main anesthetic agents. Patients were divided into groups of sevoflurane with dexmedetomidine and propofol, and the incidence of PD was evaluated in patients who underwent cardiac surgery with cardiopulmonary bypass (CPB).

\section{Methods}

\section{Study population and data collection}

After obtaining approval from the Institutional Review Board at Seoul National University Bundang Hospital (B1510/318-04), electronic medical records from January 2012 to July 2017 were reviewed retrospectively. The requirement for informed consent was waived.

Adult patients aged 20 years or over, who had undergone heart valve or CABG surgery with CPB were included in this retrospective study. Patients who had been preoperatively diagnosed with neuropsychological diseases, such as dementia or Parkinson's disease, were excluded. Patients with visual disturbances, hearing loss, or reoperation due to postoperative complications were excluded. Also, patients requiring postoperative sedation for any reason were excluded because PD might be unnoticed due to sedation.

\section{Routine general anesthesia practice}

On arrival in the operating room, standard monitoring (pulse oximetry, electrocardiogram, and noninvasive arterial pressure), bispectral index (BIS ${ }^{\mathrm{TM}}$, Covidien Icn., USA), cerebral oximeter, and invasive arterial monitoring were established. Central vein catheterization was performed after induction of general anesthesia.

During the investigation period, different general anesthetic agents had been administered to patients in our institution. Based on these different main anesthetic agents, patients were divided into two groups: sevo-dex and propofol groups. In the sevo-dex group, anesthesia was induced with intravenous propofol, remifentanil (target effect-site concentration $4 \mathrm{ng} / \mathrm{ml}$ ), and sevoflurane. During the intraoperative period, anesthesia was maintained with sevoflurane and dexmedetomidine. Dexmedetomidine (Precedex ${ }^{\mathrm{TM}}$, Hospira Inc., Lake Forest, IL, USA) was diluted with $0.9 \%$ saline to make a concentration of $4 \mu \mathrm{g} / \mathrm{ml}$ and administered continuously at $0.5 \mu \mathrm{g} / \mathrm{kg} / \mathrm{h}$. In the propofol group, total intravenous anesthesia was performed as follows: $2 \%$ propofol (Fresofolß, Fresenius Kabi, Korea Ltd, Korea) and remifentanil (Ultiva ${ }^{\circledR}$, GlaxoSmithKline, United Kingdom) diluted to $50 \mu \mathrm{g} / \mathrm{mL}$ were administered using a target-controlled infusion device (Orchestra ${ }^{\circledR}$, Fresenius vial, France) until the effect-site concentration reached $4 \mu \mathrm{g} / \mathrm{ml}$ and $4 \mathrm{ng} / \mathrm{ml}$, respectively. During surgery, propofol and remifentanil was maintained within 2.0-5.0 $\mathrm{gg} / \mathrm{ml}$ and $0.5-3.0 \mathrm{ng} / \mathrm{ml}$. Dexmedetomidine was not used in the propofol group. Bispectral index was monitored to maintain suitable anesthetic depth (40-60) in all patients. Rocuronium was administered as a neuromuscular blocking agent in both groups.

\section{Assessment of postoperative delirium}

PD was defined as the positive Confusion Assessment Method for the Intensive Care Unit (CAM-ICU) during the ICU stay. According to the standard ICU practice of our institution, CAM-ICU was examined and recorded twice a day by directed bedside nurses, who had been well trained. The type of PD was determined according to the Richmond Agitation and Sedation Scale (RASS) score. When the RASS level was positive or negative, PD was classified as 
hyperactive or hypoactive, respectively. When a patient presented with mixed positive and negative RASS scores, they were diagnosed with mixed-type PD.

After patients were transferred to the general ward, PD was assessed until postoperative day 5 by nurses based on the Nursing Delirium Screening Scale per nursing shift. While PD was identified with psychomotor retardation, it was categorized as hypoactive PD. The duration of delirium was defined as the total number of days presenting PD in ICU and general ward.

\section{Other outcome variables}

Data were collected and categorized into the following three variable sets: (1) preoperative factors, including age, sex, weight, height, body mass index, American Society of Anesthesiologist (ASA) physical status classification, and preoperative laboratory findings; (2) intraoperative factors, including the urgency of surgery, surgery time, CPB time, volume of estimated blood loss, and amount of red blood cell (RBC) transfusion; and (3) postoperative factors, including the duration of ICU stay, extubation time, postoperative admission period, postoperative complications, amount of RBC transfusion, and postoperative laboratory findings. Pre- and postoperative laboratory tests including hematocrit, platelet counts, electrolytes, creatinine, and albumin, were performed within 1 month before surgery and within $24 \mathrm{~h}$ after surgery, respectively. We investigated whether or not patients developed postoperative complications related to the renal and neurological systems.

\section{Statistical analysis}

Data are expressed as median (interquartile range) or number (proportion). All continuous data were assessed for normality using the Shapiro-Wilk test. Incidence was analyzed using the chi-square test or Fisher's exact test. The Mann-Whitney $U$ test or Wilcoxon signed rank test was performed to compare the numerical data, as appropriate. A binary logistic regression model was used to evaluate the predisposing factors of PD. The dependent variable was the occurrence of PD and the independent variables were the main anesthetic drug, age, sex, BMI, surgery type, ASA class, anesthesia time, CPB time, estimated blood loss, intraoperative and postoperative RBC transfusion amount, and preoperative and postoperative hematocrit, electrolytes, creatinine levels, and albumin level.

Propensity-score matching was performed to reduce the risk of confounder effects between the sevo-dex and propofol groups (Austin 2011). Propensity scores were calculated using a logistic regression model. Covariate included the sex, age, height, weight, BMI, ASA class, urgency of surgery, operation time, preoperative laboratory findings, estimated blood loss, duration of CPB, intra- and postoperative RBC transfused, extubation time, and type of surgery. The dependent variable was the main general anesthetic agent: inhalation with dexmedetomidine or propofol. We performed nearest-neighbor matching (Austin 2011). After propensity-score matching, the paired $t$-test or Wilcoxon signed-rank test for continuous variables and McNemar or McNemar-Bowker test for categorical variables were performed, as appropriate.

All analyses were carried out using IBM ${ }^{\circledR}$ SPSS ${ }^{\circledR}$ Statistics, version 22.0 (IBM Corporation, NY, USA). $P<0.05$ was considered to indicate statistical significance.

\section{Results}

A total of 1,283 patients were evaluated for eligibility, 534 of whom were finally analyzed. According to the main general anesthetic agent, 340 and 194 patients were assigned to the sevo-dex and propofol groups, respectively. 
After propensity-score matching, 194 patients were selected from the sevo-dex group (Figure 1).

The characteristics of patient, surgery, and anesthesia were comparable between the two groups, except for the estimated blood loss volume, intra- and postoperative RBC transfusion amount, and ICU stay period, which became comparable after propensity-score matching (Table 1).

The overall incidence, onset, and duration of PD were not significantly different between the sevo-dex and propofol groups, even after propensity-score matching (Table 2). In comparison of the incidence of each type of PD, only hyperactive PD occurred significantly less in the sevo-dex group than in the propofol group. Incidences of other postoperative complications (seizure and acute kidney injury) were comparable between the two groups (Table 2).

Preoperative hematocrit, sodium, potassium, creatinine, and albumin levels were comparable between the two groups. However, in the propofol group, lower hematocrit and potassium, and higher albumin levels were observed postoperatively compared to the sevo-dex group. These different laboratory findings became comparable after propensity-score matching (Table 3).

The following parameters were confirmed as significant determinants for the occurrence of PD by the binary logistic regression analysis (Table 4):- patients were 1.06 (95\% Cl: $1.03-1.10)$ times more likely to experience PD for every 1-year increase in age; patients with emergency surgery were 5.76 (95\% Cl: 1.66-19.98) times more likely to experience PD than patients with elective surgery; and patients were $0.46(95 \% \mathrm{Cl}: 0.22-0.98)$ times less likely to experience PD for every $1 \mathrm{~g} / \mathrm{dl}$ increase in preoperative albumin value.

\section{Discussion}

This study showed that the overall incidence of PD in cardiac surgery with CPB was not affected by the intraoperative anesthetic agent (sevoflurane with dexmedetomidine or propofol). However, hyperactive PD occurred less frequently when patients were anesthetized with sevoflurane and dexmedetomidine compared to propofol. Older age, emergency surgery, and preoperative lower albumin levels were factors contributing to PD occurrence in this study.

A recent meta-analysis reported that no significant difference was observed in the incidence of PD or postoperative cognitive impairment between the inhalation anesthetics and total intravenous anesthesia (TIVA) after CABG (Jiao et al., 2019). In non-cardiac surgery, similar results were reported via systematic review and meta-analysis that there is no evidence of a difference in incidences of PD according to type of anesthetic maintenance agents (inhalation vs. TIVA) (Miller et al., 2018). Our results demonstrated the similar results with these reports showing no difference in the incidence of PD regardless of main anesthetic agents, despite the addition of dexmedetomidine to the inhalation arm.

The role of dexmedetomidine in reducing PD has been investigated. Duan et al. reported that dexmedetomidine could reduce the PD in entire adult population undergoing cardiac or non-cardiac surgery (Duan et al., 2018). Especially, postoperative use of dexmedetomidine was proved to be effective for reducing PD in cardiac surgery compared to midazolam or propofol (Cheng et al., 2016; Djaiani et al., 2016; Maldonado et al., 2009). In noncardiac surgery, postoperative dexmedetomidine also decreased the incidence of PD (Duan et al., 2018; Su et al., 2016). However, there were still controversial results for the effect of intraoperative dexmedetomidine on PD (Duan et al., 2018). Intraoperative dexmedetomidine does not seem to have a significant effect on the reduction of PD incidence, whether in cardiac (Li et al., 2017) or non-cardiac surgery (Deiner et al., 2017). In the present study, 
dexmedetomidine was administered intraoperatively as an adjuvant to inhalation anesthesia, and consequently, no additional significant effect on PD reduction was observed.

Interestingly, the present study also showed that hyperactive PD occurred significantly less in the sevo-dex group than in the propofol group when propensity-score matching was applied. In our previous study performed in the elderly patients who had undergone orthopedic surgery under regional anesthesia (Shin et al., 2017), the postoperative agitated behavior decreased more after intraoperative dexmedetomidine sedation compared to propofol sedation. Therefore, we should consider that dexmedetomidine might play a specific role in reducing postoperative abnormal hyperactive behavior, such as agitation, confusion, and aggression. These behaviors are injurious to patients themselves and medical personnel; therefore, more studies are needed to determine if dexmedetomidine can be a potential preventive medication.

Dexmedetomidine has been known to have neuroprotective effects (Wang et al., 2018). However, the exact mechanism through which dexmedetomidine reduces the incidence of PD remains poorly understood. At present, the suggested delirium-sparing mechanisms based on the pharmacological characteristics of dexmedetomidine are as follows (Maldonado 2008; Nemoto et al., 2013; Wang et al., 2018): (1) suppression of sustained increase of $\varangle 5$ \-aminobutyric acid type A receptor expression by anesthesia; (2) maintenance of anticholinergic level; and (3) minimization of multiple neurotransmitter pathways disruption.

Risk factors for PD after cardiac surgery include advanced age, dementia, electrolyte derangement, prolonged CPB time, high perioperative transfusion requirement, preoperative low albumin levels, postoperative high C-reactive protein concentration, and longer ICU stay (Cereghetti et al., 2017; Norkiene et al., 2013). Similar contributing factors were found in the present study, which included older age, emergency surgery, and preoperative lower albumin levels. In the present study, the included patients were the entire adult patients, not the elderly. Because increased age is the risk factor of PD in cardiac surgery, it is necessary to confirm whether different results can be drawn when only elderly patients are enrolled.

Before propensity-score matching, PD has occurred $12.1 \%$ in the sevo-dex group and $10.8 \%$ in the propofol group. After propensity-score matching, the overall incidence of PD was $6 \%$ in the sevo-dex group and $10.8 \%$ in the propofol group. In the sevo-dex group, the incidence of PD decreased remarkably after propensity-score matching. First of all, mean age was decreased in the sevo-dex group by the propensity-score matching, which was proved one of the risk factor of PD occurrence. In addition, estimated blood loss, perioperative transfusion requirement, and ICU stay were corrected by the propensity-score matching. The severity of patients' condition might be corrected; therefore, the incidence of PD in the sevo-dex group seemed to be adjusted.

The present study had several limitations. First, due to the retrospective nature of this study, the anesthesia protocol was not randomized. For this reason, propensity score matching was necessary to reduce the effects of confounders in analyzing our data. Second, our sample size was lack to achieve statistical significance of the incidence of PD between the two groups. Based on a post hoc power analysis, this study has $6.3 \%$ power with a type 1 error of $5 \%$ to detect our decreased incidence of postoperative delirium in the sevo-dex group. The power increased from $6.3 \%$ to $39.9 \%$ after propensity score matching. The small cohort in each group might not have been sufficient for generalizability of results. To obtain statistical significance, more than 563 patients are required under $80 \%$ power and 0.05 type I error. Third, PD was evaluated by well-trained nurses using CAM-ICU and the Nursing Delirium Screening Scale. Because the pure hypoactive form of PD is usually more difficult to detect than the hyperactive form, the hypoactive form of PD might have been missed although the RASS score was assessed 
with CAM-ICU. Furthermore, although use of the CAM-ICU by nurses was previously validated (Ely et al., 2001), the consistency by which delirium was measured may not have been similar across all patients. Also, delirium is a waxing and waning condition, and delirious episodes could have been missed in some patients at the times delirium was measured. Finally, this study was performed using data from a single center; therefore, the generalizability may be compromised.

In conclusion, the overall incidence of PD after cardiac surgery with CPB is not associated with the main anesthetic agent, sevoflurane and dexmedetomidine-based $v s$. propofol-based anesthesia. Only hyperactive PD occurred less frequently in patients receiving sevoflurane and dexmedetomidine-based anesthesia. Further large randomized controlled trials are required to confirm the impact of the anesthetic on the postoperative delirium.

\section{Declarations}

Financial disclosures

None.

\section{Authors' contribution}

Hyun-Jung Shin: concept/design, data collection, drafting article, approval of article. Soo Lyoen Choi: data collection, approval of article. Hyo-Seok Na: concept/design, critical revision of article, approval of article. All authors read and approved the final manuscript.

\section{Funding}

None

\section{Availability of data and materials}

The datasets generated and/or analyzed during the current study are not publicly available due to the regulation of Institutional Review Board, but are available from the corresponding author after getting permission from IRB for sharing the dataset on reasonable request.

\section{Ethics approval and consent to participate}

After obtaining approval from the Institutional Review Board at Seoul National University Bundang Hospital (B1510/318-04), electronic medical records from January 2012 to July 2017 were reviewed. The requirement for informed consent was waived.

\section{Consent for publication}

Not applicable.

\section{Competing interests}

The authors declare that they have no competing interests

\section{Author details}


Department of Anesthesiology and Pain Medicine, Seoul National University Bundang Hospital, 82, Gumi-ro 173beon-gil, Bundang, Seongnam 13620, South Korea.

\section{Abbreviations}

ASA: American Society of Anesthesiologist; CABG: coronary artery bypass graft; CAM-ICU: confusion Assessment Method for the Intensive Care Unit; CPB: cardiopulmonary bypass; PD: postoperative delirium; RASS: Richmond Agitation and Sedation Scale; RBC: red blood cell.

\section{References}

1. Austin PC. An Introduction to Propensity Score Methods for Reducing the Effects of Confounding in Observational Studies. Multivariate Behav Res 2011;46(3): 399-424.

2. Cereghetti C, Siegemund M, Schaedelin S, Fassl J, Seeberger MD, Eckstein FS, et al. Independent Predictors of the Duration and Overall Burden of Postoperative Delirium After Cardiac Surgery in Adults: An Observational Cohort Study. J Cardiothorac Vasc Anesth 2017;31(6): 1966-73.

3. Chaput AJ and Bryson GL. Postoperative delirium: risk factors and management: continuing professional development. Can J Anaesth 2012;59(3): 304-20.

4. Cheng H, Li Z, Young N, Boyd D, Atkins Z, Ji F, et al. The Effect of Dexmedetomidine on Outcomes of Cardiac Surgery in Elderly Patients. J Cardiothorac Vasc Anesth 2016;30(6): 1502-8.

5. Deiner S, Luo X, Lin HM, Sessler DI, Saager L, Sieber FE, et al. Intraoperative Infusion of Dexmedetomidine for Prevention of Postoperative Delirium and Cognitive Dysfunction in Elderly Patients Undergoing Major Elective Noncardiac Surgery: A Randomized Clinical Trial. JAMA Surg 2017;152(8): e171505.

6. Djaiani G, Silverton N, Fedorko L, Carroll J, Styra R, Rao V, et al. Dexmedetomidine versus Propofol Sedation Reduces Delirium after Cardiac Surgery: A Randomized Controlled Trial. Anesthesiology 2016;124(2): $362-8$.

7. Duan X, Coburn M, Rossaint R, Sanders RD, Waesberghe JV, Kowark A. Efficacy of perioperative dexmedetomidine on postoperative delirium: systematic review and meta-analysis with trial sequential analysis of randomised controlled trials. Br J Anaesth 2018;121(2): 384-97.

8. Ely EW, Margolin R, Francis J, May L, Truman B, Dittus R, et al. Evaluation of delirium in critically ill patients: validation of the Confusion Assessment Method for the Intensive Care Unit (CAM-ICU). Crit Care Med 2001;29(7): 1370-9.

9. Evans AS, Weiner MM, Arora RC, Chung I, Deshpande R, Varghese R, et al. Current approach to diagnosis and treatment of delirium after cardiac surgery. Ann Card Anaesth 2016;19(2): 328-37.

10. Hollinger A, Siegemund M, Goettel N, Steiner LA. Postoperative Delirium in Cardiac Surgery: An Unavoidable Menace? J Cardiothorac Vasc Anesth 2015;29(6): 1677-87.

11. Jiao XF, Lin XM, Ni XF, Li HL, Zhang C, Yang CS, et al. Volatile anesthetics versus total intravenous anesthesia in patients undergoing coronary artery bypass grafting: An updated meta-analysis and trial sequential analysis of randomized controlled trials. PLoS One 2019;14(10): e0224562.

12. Li X, Yang J, Nie XL, Zhang Y, Li XY, Li LH, et al. Impact of dexmedetomidine on the incidence of delirium in elderly patients after cardiac surgery: A randomized controlled trial. PLoS One 2017;12(2): e0170757.

13. Lin Y, Chen J, Wang Z. Meta-analysis of factors which influence delirium following cardiac surgery. J Card Surg 2012;27(4): 481-92. 
14. Maldonado JR. Pathoetiological model of delirium: a comprehensive understanding of the neurobiology of delirium and an evidence-based approach to prevention and treatment. Crit Care Clin 2008;24(4): 789-856, ix.

15. Maldonado JR, Wysong A, van der Starre PJ, Block T, Miller C, Reitz BA. Dexmedetomidine and the reduction of postoperative delirium after cardiac surgery. Psychosomatics 2009;50(3): 206-17.

16. Miller D, Lewis SR, Pritchard MW, Schofield-Robinson OJ, Shelton CL, Alderson P, et al. Intravenous versus inhalational maintenance of anaesthesia for postoperative cognitive outcomes in elderly people undergoing non-cardiac surgery. Cochrane Database Syst Rev 2018;8: CD012317.

17. Nemoto C, Murakawa M, Hakozaki T, Imaizumi T, Isosu T, Obara S. Effects of dexmedetomidine, midazolam, and propofol on acetylcholine release in the rat cerebral cortex in vivo. J Anesth 2013;27(5): 771-4.

18. Norkiene I, Ringaitiene D, Kuzminskaite V, Sipylaite J. Incidence and risk factors of early delirium after cardiac surgery. Biomed Res Int 2013;2013: 323491.

19. Oh CS, Park S, Wan Hong S, Kang WS, Yoon TG, Kim SH. Postoperative Delirium in Patients Undergoing OffPump Coronary Artery Bypass Grafting According to the Anesthetic Agent: A Retrospective Study. J Cardiothorac Vasc Anesth 2017;31(6): 1988-95.

20. Royse CF, Andrews DT, Newman SN, Stygall J, Williams Z, Pang J, et al. The influence of propofol or desflurane on postoperative cognitive dysfunction in patients undergoing coronary artery bypass surgery. Anaesthesia 2011;66(6): 455-64.

21. Saczynski JS, Marcantonio ER, Quach L, Fong TG, Gross A, Inouye SK, et al. Cognitive trajectories after postoperative delirium. N Engl J Med 2012;367(1): 30-9.

22. Schoen J, Husemann L, Tiemeyer C, Lueloh A, Sedemund-Adib B, Berger KU, et al. Cognitive function after sevoflurane- vs propofol-based anaesthesia for on-pump cardiac surgery: a randomized controlled trial. $\mathrm{Br} \mathrm{J}$ Anaesth 2011;106(6): 840-50.

23. Shin HJ, Koo BW, Bang SU, Kim JH, Hwang JW, Do SH, et al. Intraoperative dexmedetomidine sedation reduces the postoperative agitated behavior in elderly patients undergoing orthopedic surgery compared to the propofol sedation. Minerva Anestesiol 2017;83(10): 1042-50.

24. Su X, Meng ZT, Wu XH, Cui F, Li HL, Wang DX, et al. Dexmedetomidine for prevention of delirium in elderly patients after non-cardiac surgery: a randomised, double-blind, placebo-controlled trial. Lancet 2016;388(10054): 1893-902.

25. Wang DS, Kaneshwaran K, Lei G, Mostafa F, Wang J, Lecker I, et al. Dexmedetomidine Prevents Excessive gamma-Aminobutyric Acid Type A Receptor Function after Anesthesia. Anesthesiology 2018;129(3): 477-89.

26. Xie S and Xie M. Effect of dexmedetomidine on postoperative delirium in elderly patients undergoing hip fracture surgery. Pak J Pharm Sci 2018;31(5(Special)): 2277-81.

\section{Tables}

Table 1 Characteristics of patients, surgery, and anesthesia 


\begin{tabular}{|c|c|c|c|c|c|c|}
\hline & \multicolumn{3}{|c|}{ Before matching } & \multicolumn{3}{|c|}{ After matching } \\
\hline & Sevo-Dex & Propofol & $\begin{array}{l}P \\
\text { value }\end{array}$ & Sevo-Dex & Propofol & $\begin{array}{l}P \\
\text { value }\end{array}$ \\
\hline & $(N=340)$ & $(N=194)$ & & $(N=194)$ & $(N=194)$ & \\
\hline Age (year) & $70(58-76)$ & $68(56-76)$ & 0.240 & $\begin{array}{l}65(56- \\
74)\end{array}$ & $\begin{array}{l}68(56- \\
76)\end{array}$ & 0.483 \\
\hline Gender & & & 0.368 & & & 0.845 \\
\hline Male & 169 (50\%) & $105(54 \%)$ & & $108(56 \%)$ & $105(54 \%)$ & \\
\hline Female & $171(50 \%)$ & $89(46 \%)$ & & $86(44 \%)$ & $89(46 \%)$ & \\
\hline Weight (kg) & $64(57-71)$ & $65(58-71)$ & 0.445 & $\begin{array}{l}66(57- \\
73)\end{array}$ & $\begin{array}{l}65(58- \\
71)\end{array}$ & 0.940 \\
\hline Height (cm) & $\begin{array}{l}160(153- \\
168)\end{array}$ & $\begin{array}{l}163(155- \\
169)\end{array}$ & 0.053 & $\begin{array}{l}162(154- \\
170)\end{array}$ & $\begin{array}{l}163(155- \\
169)\end{array}$ & 0.977 \\
\hline BMI $\left(\mathrm{kg} / \mathrm{m}^{2}\right)$ & $25(22-27)$ & $24(23-27)$ & 0.805 & $\begin{array}{l}24(23- \\
27)\end{array}$ & $\begin{array}{l}24(23- \\
27)\end{array}$ & 0.781 \\
\hline ASA classification $(1 / 2 / 3)$ & & & 0.318 & & & 0.903 \\
\hline 1 & 7 & 1 & & 1 & 1 & \\
\hline 2 & 64 & 38 & & 43 & 38 & \\
\hline 3 & 253 & 141 & & 140 & 141 & \\
\hline 4 & 16 & 14 & & 10 & 14 & \\
\hline Surgery time (min) & $\begin{array}{l}260(216- \\
305)\end{array}$ & $\begin{array}{l}245(215- \\
300)\end{array}$ & 0.364 & $\begin{array}{l}255(215- \\
300)\end{array}$ & $\begin{array}{l}245(215- \\
300)\end{array}$ & 0.867 \\
\hline Anesthesia time (min) & $\begin{array}{l}305(265- \\
355)\end{array}$ & $\begin{array}{l}300(265- \\
345)\end{array}$ & 0.398 & $\begin{array}{l}300(264- \\
340)\end{array}$ & $\begin{array}{l}300(265- \\
345)\end{array}$ & 0.571 \\
\hline Estimated blood loss ( $\mathrm{mL}$ ) & $\begin{array}{l}900(600- \\
1275)\end{array}$ & $\begin{array}{l}800(500- \\
1000)\end{array}$ & 0.002 & $\begin{array}{l}800(500- \\
1000)\end{array}$ & $\begin{array}{l}800(500- \\
1000)\end{array}$ & 0.866 \\
\hline RBCs ( $m L$, during surgery) & $\begin{array}{l}750(400- \\
1200)\end{array}$ & $\begin{array}{l}600(200- \\
1000)\end{array}$ & 0.008 & $\begin{array}{l}500(0- \\
954)\end{array}$ & $\begin{array}{l}600(200- \\
1000)\end{array}$ & 0.354 \\
\hline RBCs (mL, after surgery) & $0(0-250)$ & $0(0-500)$ & $<0.001$ & $0(0-250)$ & $0(0-500)$ & 0.321 \\
\hline CPB (min) & $\begin{array}{l}125(93- \\
155)\end{array}$ & $\begin{array}{l}124(98- \\
146)\end{array}$ & 0.344 & $\begin{array}{l}123(90- \\
148)\end{array}$ & $\begin{array}{l}124(98- \\
146)\end{array}$ & 0.454 \\
\hline Elective/emergency & $\begin{array}{l}322 \\
(95 \%) / 18 \\
(5 \%)\end{array}$ & $\begin{array}{l}190 \\
(98 \%) / 4 \\
(2 \%)\end{array}$ & 0.075 & $\begin{array}{l}189 \\
(97 \%) / 5 \\
(3 \%)\end{array}$ & $\begin{array}{l}190 \\
(98 \%) / 4 \\
(2 \%)\end{array}$ & 1.000 \\
\hline Extubation (days) & $0(0-1)$ & $0(0-1)$ & 0.286 & $0(0-1)$ & $0(0-1)$ & 0.962 \\
\hline ICU stay (days) & $2(1-2)$ & $1(1-2)$ & 0.024 & $1(1-2)$ & $1(1-2)$ & 0.265 \\
\hline $\begin{array}{l}\text { Postoperative hospital } \\
\text { stay (days) }\end{array}$ & $9(7-14)$ & $9(7-13)$ & 0.473 & $8(7-12)$ & $9(7-13)$ & 0.331 \\
\hline
\end{tabular}


Data are expressed as the median (interquartile range) or the number of the patients (proportion).

BMI, body mass index; ASA, American Society of Anesthesiologist classification; RBC, red blood cell; CPB, cardiopulmonary bypass; ICU, intensive care unit. Sevo-Dex, sevoflurane + dexmedetomidine.

Table 2 Characteristics of postoperative delirium and complications

\begin{tabular}{|c|c|c|c|c|c|c|}
\hline & \multicolumn{3}{|c|}{ Before matching } & \multicolumn{3}{|c|}{ After matching } \\
\hline & $\begin{array}{l}\text { Sevo- } \\
\text { Dex }\end{array}$ & Propofol & $\begin{array}{l}P \\
\text { value }\end{array}$ & $\begin{array}{l}\text { Sevo- } \\
\text { Dex }\end{array}$ & Propofol & $\begin{array}{l}P \\
\text { value }\end{array}$ \\
\hline & $(\mathrm{N}=340)$ & $(\mathrm{N}=194)$ & & $(\mathrm{N}=194)$ & $(\mathrm{N}=194)$ & \\
\hline PD (overall) & $\begin{array}{l}41 \\
(12.1 \%)\end{array}$ & $\begin{array}{l}21 \\
(10.8 \%)\end{array}$ & 0.779 & $12(6 \%)$ & $\begin{array}{l}21 \\
(10.8 \%)\end{array}$ & 0.136 \\
\hline Hyperactive PD & $26(7.6 \%)$ & $14(7.2 \%)$ & 1.000 & $4(2.1 \%)$ & $14(7.2 \%)$ & 0.021 \\
\hline Hypoactive PD & $12(3.5 \%)$ & $5(2.6 \%)$ & 0.618 & $5(2.6 \%)$ & $5(2.6 \%)$ & 1.000 \\
\hline Mixed PD & $3(0.9 \%)$ & $2(1.0 \%)$ & 1.000 & $3(1.5 \%)$ & $2(1.0 \%)$ & 1.000 \\
\hline $\begin{array}{l}\text { Onset delirium (postoperative } \\
\text { day)* }\end{array}$ & $\begin{array}{l}1.83 \\
(1.38)\end{array}$ & $\begin{array}{l}1.57 \\
(0.98)\end{array}$ & 0.710 & $\begin{array}{l}1.67 \\
(1.43)\end{array}$ & $\begin{array}{l}1.57 \\
(0.98)\end{array}$ & 0.194 \\
\hline Duration of delirium (day)* & $\begin{array}{l}2.27 \\
(2.61)\end{array}$ & $\begin{array}{l}1.57 \\
(0.87)\end{array}$ & 0.154 & $\begin{array}{l}2.08 \\
(1.93)\end{array}$ & $\begin{array}{l}1.57 \\
(0.87)\end{array}$ & 0.153 \\
\hline Seizure & $11(3.2 \%)$ & $2(1.0 \%)$ & 0.148 & $7(3.6 \%)$ & $2(1.0 \%)$ & 0.180 \\
\hline Acute kidney injury & $2(0.6 \%)$ & $1(0.5 \%)$ & 1.000 & $1(0.5 \%)$ & $1(0.5 \%)$ & 1.000 \\
\hline
\end{tabular}

Data are expressed as the mean (SD) or number of the patients (proportion)

PD, postoperative delirium. Sevo-Dex, sevoflurane + dexmedetomidine.

*These data were calculated only in patients presenting PD of each group.

Table 3 Preoperative and postoperative laboratory results 


\begin{tabular}{|c|c|c|c|c|c|c|}
\hline \multirow{3}{*}{-} & \multicolumn{6}{|c|}{ Before matching } \\
\hline & \multicolumn{2}{|c|}{ Sevo-Dex $(\mathrm{N}=340)$} & \multicolumn{4}{|c|}{ Propofol $(\mathrm{N}=194)$} \\
\hline & Preoperative & Postoperative & Preoperative & Postoperative & $P_{1}$ & $P_{2}$ \\
\hline $\begin{array}{l}\text { Hematocrit } \\
(\%)\end{array}$ & $\begin{array}{l}12.8(11.2- \\
14.2)\end{array}$ & $11.1(10.1-12.1)$ & $\begin{array}{l}13.0(11.5- \\
14.3)\end{array}$ & $\begin{array}{l}10.6(9.5- \\
12.0)^{(9-}\end{array}$ & 0.269 & 0.028 \\
\hline $\begin{array}{l}\text { Sodium } \\
(\mathrm{mmol} / \mathrm{L})\end{array}$ & $\begin{array}{l}139(136- \\
141)\end{array}$ & 139 (137-141) & $\begin{array}{l}139(137- \\
141)\end{array}$ & $\begin{array}{l}139(137- \\
141)\end{array}$ & 0.367 & 0.171 \\
\hline $\begin{array}{l}\text { Potassium } \\
(\mathrm{mmol} / \mathrm{L})\end{array}$ & $\begin{array}{l}4.2(3.9- \\
4.4)\end{array}$ & $3.9(3.6-4.2)$ & $\begin{array}{l}4.1(3.9- \\
4.4)\end{array}$ & $3.8(3.4-4.1)$ & 0.438 & 0.026 \\
\hline $\begin{array}{l}\text { Creatinine } \\
(\mathrm{mg} / \mathrm{dL})\end{array}$ & $\begin{array}{l}0.86(0.70- \\
1.05)\end{array}$ & $0.88(0.74-1.09)$ & $\begin{array}{l}0.84(0.66- \\
0.99)\end{array}$ & $\begin{array}{l}0.93(0.77- \\
1.15)\end{array}$ & 0.117 & 0.117 \\
\hline \multirow[t]{2}{*}{$\begin{array}{l}\text { Albumin } \\
(\mathrm{g} / \mathrm{dL})\end{array}$} & $\begin{array}{l}4.1(3.6- \\
4.4)\end{array}$ & $3.3(3.0-3.7)$ & $\begin{array}{l}4.1(3.8- \\
4.4)\end{array}$ & $3.4(3.1-3.7)$ & 0.336 & 0.040 \\
\hline & \multicolumn{6}{|c|}{ After matching } \\
\hline- & \multicolumn{2}{|c|}{ Sevo-Dex $(N=194)$} & \multicolumn{2}{|c|}{$\begin{array}{l}\text { Propofol }(\mathrm{N}= \\
194)\end{array}$} & & \\
\hline - & Preoperative & Postoperative & Preoperative & Postoperative & $P_{1}$ & $P_{2}$ \\
\hline $\begin{array}{l}\text { Hematocrit } \\
(\%)\end{array}$ & $\begin{array}{l}13.1(11.8- \\
14.5)\end{array}$ & $\begin{array}{l}10.9(9.7- \\
11.8)\end{array}$ & $\begin{array}{l}13.0(11.5- \\
14.3)\end{array}$ & $\begin{array}{l}10.6(9.5- \\
12.0)^{(9-}\end{array}$ & 0.573 & 0.692 \\
\hline $\begin{array}{l}\text { Sodium } \\
(\mathrm{mmol} / \mathrm{L})\end{array}$ & $139(137-141)$ & $\begin{array}{l}139(137- \\
141)\end{array}$ & $\begin{array}{l}139(137- \\
141)\end{array}$ & $\begin{array}{l}139(137- \\
141)\end{array}$ & 0.598 & 0.982 \\
\hline $\begin{array}{l}\text { Potassium } \\
(\mathrm{mmol} / \mathrm{L})\end{array}$ & $4.2(3.9-4.4)$ & $3.8(3.5-4.1)$ & $\begin{array}{l}4.1(3.9- \\
4.4)\end{array}$ & $3.8(3.4-4.1)$ & 0.894 & 0.899 \\
\hline $\begin{array}{l}\text { Creatinine } \\
(\mathrm{mg} / \mathrm{dL})\end{array}$ & $\begin{array}{l}0.84(0.70- \\
0.99)\end{array}$ & $\begin{array}{l}0.88(0.76- \\
1.07)\end{array}$ & $\begin{array}{l}0.84(0.66- \\
0.99)\end{array}$ & $\begin{array}{l}0.93(0.77- \\
1.15)\end{array}$ & 0.776 & 0.093 \\
\hline $\begin{array}{l}\text { Albumin } \\
(\mathrm{g} / \mathrm{dL})\end{array}$ & $4.2(3.8-4.5)$ & $3.4(3.1-3.8)$ & $\begin{array}{l}4.1(3.8- \\
4.4)\end{array}$ & $3.4(3.1-3.7)$ & 0.383 & 0.645 \\
\hline
\end{tabular}

Data are expressed as the median (interquartile range)

P1: compared the preoperative values between the two groups, P2: compared the postoperative values between the two groups.

Sevo-Dex, sevoflurane + dexmedetomidine.

Table 4. Binary logistic regression for the occurrence of postoperative delirium 


\begin{tabular}{|c|c|c|}
\hline Independent variables & OR $(95 \% \mathrm{Cl})$ & $P$ \\
\hline Drug for anesthesia & & 0.340 \\
\hline Propofol & 1 & \\
\hline Sevo-Dex & $0.71(0.35-1.44)$ & \\
\hline Age (year) & $1.06(1.03-1.10)$ & $<0.001$ \\
\hline Gender & & 0.839 \\
\hline Male & 1 & \\
\hline Female & $1.11(0.40-3.12)$ & \\
\hline BMI $\left(\mathrm{kg} / \mathrm{m}^{2}\right)$ & $0.83(0.59-1.18)$ & 0.295 \\
\hline Elective/emergency & & 0.006 \\
\hline Elective & 1 & \\
\hline Emergency & $5.76(1.66-19.98)$ & \\
\hline ASA & & 0.673 \\
\hline 1 & $0.26(0.02-4.08)$ & 0.341 \\
\hline 2 & $0.17(0.01-2.42)$ & 0.190 \\
\hline 3 & $0.19(0.01-3.18)$ & 0.247 \\
\hline 4 & 0.00 & 1.000 \\
\hline Anesthesia time (min) & $1.01(0.99-1.02)$ & 0.081 \\
\hline CPB time (min) & $1.01(0.99-1.02)$ & 0.145 \\
\hline Estimated blood loss (ml) & $1.00(1.00-1.00)$ & 0.521 \\
\hline RBCs (mL, during surgery) & $1.00(1.00-1.00)$ & 0.154 \\
\hline RBCs (mL, after surgery) & $1.00(1.00-1.00)$ & 0.076 \\
\hline \multicolumn{3}{|c|}{ Preoperative laboratory findings } \\
\hline Hematocrit (\%) & $1.12(0.90-1.39)$ & 0.314 \\
\hline Sodium (mmol/L) & $0.99(0.89-1.10)$ & 0.827 \\
\hline Potassium (mmol/L) & $0.89(0.42-1.90)$ & 0.761 \\
\hline Creatinine (mg/dL) & $1.78(0.82-3.97)$ & 0.146 \\
\hline Albumin (g/dL) & $0.46(0.22-0.98)$ & 0.043 \\
\hline \multicolumn{3}{|c|}{ Postoperative laboratory findings } \\
\hline Hematocrit (\%) & $0.94(0.76-1.17)$ & 0.604 \\
\hline Sodium (mmol/L) & $0.90(0.79-1.03)$ & 0.123 \\
\hline Potassium (mmol/L) & $0.84(0.39-1.78)$ & 0.644 \\
\hline
\end{tabular}

Page 13/15 


\begin{tabular}{|lll|}
\hline Creatinine $(\mathrm{mg} / \mathrm{dL})$ & $0.53(0.20-1.40)$ & 0.199 \\
\hline Albumin $(\mathrm{g} / \mathrm{dL})$ & $0.96(0.48-1.93)$ & 0.910 \\
\hline
\end{tabular}

OR, odds ratio; Cl, confidence interval; BMI, Body mass index; ASA, American Society of Anesthesiologist; CPB, cardiopulmonary bypass. Sevo-Dex, sevoflurane + dexmedetomidine.

\section{Figures}

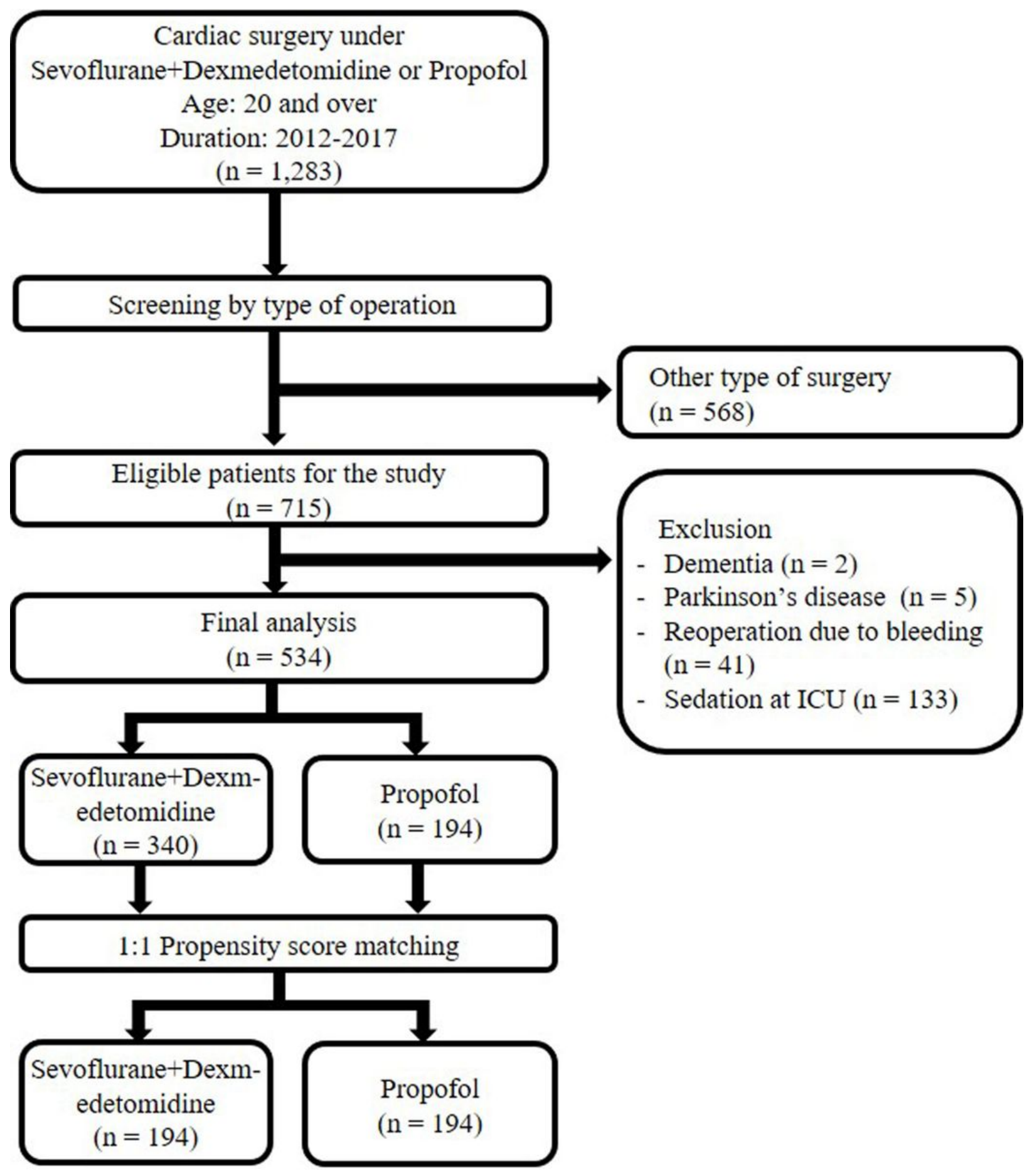

Figure 1 
Flow chart ICU, intensive care unit

Page 15/15 